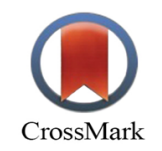

\title{
Association of Gastrointestinal Functional Disorders and Migraine Headache: a Population Base Study
}

\author{
Kamran B Lankarani ${ }^{1, *}$, Maryam Akbari ${ }^{1}$, Reza Tabrizi ${ }^{1}$
}

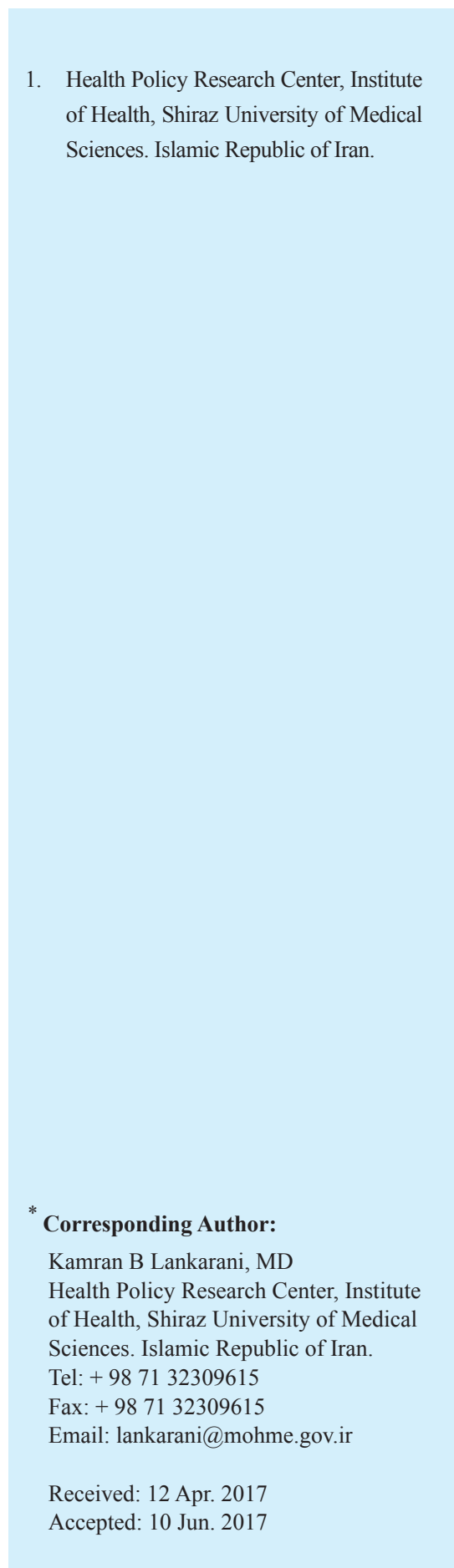

\section{ABSTRACT}

\section{BACKGROUND}

Migraine is one of the prevalent headaches. Many of patients with migraine, complain of gastrointestinal symptoms. There is limited studies on relation of gastrointestinal symptoms and migraine headache at population level.

\section{METHODS}

In this population-based study, 1038 subjects older than 15 year from a rural area in Fars province, south of Iran. were investigated for functional gastrointestinal disorders. By cluster random sampling, 160 of these persons invited to receive endoscopy along with histopathology samples of upper gastrointestinal tract. Data were analyzed using Pearson chi-square and Fisher exact.

\section{RESULTS}

Mean age of participations were 34.3 years with female to male of $3: 1$. The prevalence of migraine, irritable bowel syndrome (IBS), reflux, and dyspepsia were $24.6 \%, 17.7 \%, 17.4 \%$, and $32.1 \%$, respectively. There were significant relationship between migraine and functional gastrointestinal diseases (odds ratio of association for migraine with IBS, reflux, and dyspepsia were $3.43,1.68$, and 1.68 with $p$-value $<0.001$ for all). In endoscopic findings, only presence of hiatal hernia was associated significantly with migraine $(p=0.011)$. No histopathologic findings in antral or duodenal biopsies were associated with migraine.

\section{CONCLUSION}

In this population based study we found significant association between migraines and gastrointestinal functional disorders including IBS, reflux and dyspepsia. This may have implication in better management of patients with migraine headache.

\section{KEYWORDS:}

Migraine, Headache, Irritable bowel syndrome, Reflux, Dyspepsia, Population-based study.

Please cite this paper as:

Lankarani K.B, Akbari M, Tabrizi R. Association of Gastrointestinal Functional Disorders and Migraine Headache: a Population Base Study. Middle East J Dig Dis 2017;9:139-145. DOI: $10.15171 /$ mejdd.2017.64.

\section{INTRODUCTION}

Migraine is a disabling chronic headache defined according to the International Classification of Headache Disorders as "recurrent, moderate to severe headache attacks lasting 4-72 $\mathrm{h}$ with associated features including nausea and/or vomiting". ${ }^{1}$ Migraine is one of the most prevalent medical disorders worldwide specially in out patients departments ${ }^{2}$ and is considered as a major cause of the global burden of disease..$^{2-3}$

Migraine is a multifactorial disease; with significant role for environmental and genetic factors. ${ }^{4}$ Many co morbidities including psychiatric, cardiovascular and pulmonary disorders have been reported in patients suffering from migraine. ${ }^{5-6}$

There are limited number of studies on association of migraine and functional gastrointestinal disorders (FGD) but most of them have some bias and a few 
number of these studies are truly population based..$^{6-9}$ This association might be related to gastrointestinal side effects of analgesics or other drugs used in the management of migraine. ${ }^{10}$ Although few studies suggested Helicobacter pylori infection as a pathogenic factor for migraine, ${ }^{11}$ but other studies have not observed correlation between Helicobacter pylori infection and migraine. ${ }^{12-13}$

Considering the contradictory findings in previous studies, this study was designed to investigate the prevalence and association between migraine and FGD including IBS, reflux, and dyspepsia in a population-based study in Fars, southern Iran.

\section{MATERIALS AND METHODS}

This cross-sectional population-based study was conducted in two phases in a Baladeha village near Kazerun west of Fars province, Iran. Its population was 1848 subjects at the time of study of whom 1118 persons were older than 15 years. In first phase, all persons older than 15 years were invited to participate in a medical interview. Of them 1038 (92.8\%) joined in by coming to health care center in this region. A Three-dimensional questionnaire was completed by physicians' interview. First dimension was on demographic characteristics of the participants (such as gender, age, family size, literacy level, and marital status). The second dimension of questionnaire included questions on presence of migraine headache symptoms based on the latest criteria of International Headache Society. ${ }^{14}$ The third dimension contained questions on gastrointestinal functional disorders symptoms according to Rome III criteria. ${ }^{15}$ We used backward and forward method to translate these two questionnaires into Persian version until all difference and discrepancies were corrected. These questionnaires were validated by the study group in interviewing 50 persons in the same village. A standard medical history and physical examination was also done for all participants by the same physicians.

Those individuals who had any chronic disease including diabetes mellitus, hypertension, any cardiovascular disease, osteoarthritis, neurological disorders, documented organic gastrointestinal diseases, and recipients of treatment for migraine headache were excluded based on medical history and physical examination by the medical team consistent of four physicians.

In the second phase participants were classified into four groups based on the presence of migraine symptoms and FGD; 1) individuals with migraine and gastrointestinal symptoms 2) individual with migraine and without gastrointestinal symptoms 3) individuals without migraine but with gastrointestinal symptoms 4) individuals without migraine and gastrointestinal symptoms. For each group, 40 individuals were selected randomly based on numbers and were invited for upper gastrointestinal tract endoscopy after overnight fasting. Those with any type of heart or pulmonary diseases were excluded from invitation for endoscopy. Before endoscopy informed consent was acquired from all precipitants. Endoscopy was done by a gastroenterologist who did not know the participants' category. In endoscopy, all parts of the upper gastrointestinal tract were examined. Two biopsies from antrum, gastric body and the first and second part of the duodenum were taken in all of endoscopies using standard biopsy forceps. Any suspected lesions were also biopsied. Samples were reviewed by a pathologist who was also blind to the subjects' categories and the endoscopy findings.

\section{Statistical analysis}

Data were analyzed by SPSS software version 20 (SPSS, Chicago, IL, USA). Statistical analyses were performed using Chi-square test (Fisher's exact test) and independent-samples t-test (or Mann Withney U). $P$-value of $<0.05$ was considered statistically significant.

\section{Ethics}

The project was approved by the ethical committee of the Shiraz University of Medical Sciences.

\section{RESULTS}

1038 individuals older than 15 years participated in this study. Of these 755 (56.4\% female) fulfilled the inclusion criteria. The levels of educations' participants were $38.9 \%$ (404) illiterate, $40.3 \%$ (418) less than middle school, $17.6 \%$ (183) less than high school, and 3.2\% (33) had university education. $61 \%$ (638) lived in a family with more than 5 people. The mean age of participants was 34.3 years (range: 15 to 87 years).

Table 1 demonstrates the prevalence and association of migraine and FGD with demographic variables in our study. $24.6 \%$ (246) participants by international head- 
Table 1: Demographic characteristics and the relationship these with considered diseases

\begin{tabular}{|c|c|c|c|c|c|c|c|c|c|c|c|c|c|}
\hline \multicolumn{2}{|c|}{ Variables } & N. Mi & Mi & $\mathbf{P}$ & N.IBS & IBS & $\mathbf{P}$ & N.Ref & Ref & $\mathbf{P}$ & N.Su & Su & p \\
\hline \multirow[t]{4}{*}{ Gender } & Male & 329 & 54 & $<0.001$ & 334 & 61 & 0.131 & 320 & 67 & 0.945 & 285 & 102 & 0.002 \\
\hline & & (43.6) & (22) & & (39.1) & $(33.2)$ & & (37.9) & $(37.6)$ & & (41.1) & (31.1) & \\
\hline & Female & 426 & 192 & & 520 & 123 & & 524 & 111 & & 409 & 226 & \\
\hline & & (56.4) & (78) & & $(60.9)$ & $(66.8)$ & & $(62.1)$ & $(62.4)$ & & (58.9) & (68.9) & \\
\hline \multirow[t]{12}{*}{$\begin{array}{l}\text { Age } \\
\text { groups }\end{array}$} & $15-24$ & 272 & 69 & 0.329 & 284 & 67 & 0.604 & 298 & 50 & 0.189 & 250 & 98 & 0.061 \\
\hline & & (36) & (28) & & $(33.5)$ & $(36.4)$ & & (35.3) & $(28.1)$ & & (36) & (29.9) & \\
\hline & $25-34$ & 205 & 76 & & 238 & 56 & & 239 & 50 & & 186 & 103 & \\
\hline & & $(27.2)$ & (30.9) & & (27.9) & $(30.4)$ & & $(28.3)$ & $(28.1)$ & & $(26.8)$ & (31.4) & \\
\hline & $35-44$ & 117 & 45 & & 136 & 30 & & 137 & 27 & & 102 & 62 & \\
\hline & & (15.5) & (18.3) & & (15.9) & (16.3) & & (16.2) & (15.1) & & (14.7) & (18.9) & \\
\hline & $45-54$ & 61 & 20 & & 73 & 12 & & 64 & 19 & & 64 & 19 & \\
\hline & & (8.1) & (8.1) & & (8.5) & (6.5) & & (7.6) & $(10.7)$ & & $(9.2)$ & $(5.8)$ & \\
\hline & $55-64$ & 71 & 27 & & 86 & 15 & & 76 & 24 & & 64 & 36 & \\
\hline & & (9.4) & (11) & & $(15.1)$ & (8.2) & & (9) & (13.5) & & $(9.2)$ & (11) & \\
\hline & $=>65$ & 29 & 9 & & 35 & 4 & & 30 & 8 & & 28 & 15 & \\
\hline & & (3.8) & (3.7) & & (4.1) & $(2.2)$ & & (3.6) & $(4.5)$ & & (1.4) & (3) & \\
\hline \multirow[t]{8}{*}{ Literacy } & Illiterate & 268 & 120 & $<0.001$ & 334 & 70 & 0.634 & 311 & 87 & 0.008 & 262 & 136 & 0.421 \\
\hline & & $(35.5)$ & $(48.8)$ & & (39.1) & (38) & & $(36.8)$ & (48.9) & & $(37.8)$ & $(41.5)$ & \\
\hline & $\begin{array}{l}\text { Less than } \\
\text { middle school }\end{array}$ & 305 & 97 & & 337 & 81 & & 343 & 67 & & 283 & 127 & \\
\hline & & $(40.4)$ & (39.4) & & $(39.5)$ & (44) & & $(40.6)$ & $(37.6)$ & & $(40.8)$ & $(38.7)$ & \\
\hline & $\begin{array}{l}\text { Less than } \\
\text { middle school }\end{array}$ & 154 & 25 & & 155 & 28 & & 162 & 19 & & 123 & 58 & \\
\hline & & (20.4) & $(10.2)$ & & $(18.1)$ & $(15.2)$ & & (19.2) & $(10.7)$ & & (17.7) & (17.7) & \\
\hline & University & 28 & 4 & & 28 & 5 & & 28 & 5 & & 26 & 7 & \\
\hline & education & (3.7) & (1.6) & & (3.3) & (2.7) & & $(3.4)$ & (2.8) & & (3.7) & $(2.1)$ & \\
\hline \multirow[t]{4}{*}{ Marital } & Single & 210 & 46 & 0.004 & 223 & 46 & 0.754 & 232 & 31 & 0.005 & 196 & 67 & 0.008 \\
\hline & & $(27.8)$ & $(18.7)$ & & $(26.1)$ & (25) & & $(27.5)$ & (17.4) & & $(28.2)$ & (20.4) & \\
\hline & Married & 545 & 200 & & 631 & 138 & & 612 & 147 & & 498 & 291 & \\
\hline & & $(72.2)$ & $(81.3)$ & & (73.9) & (75) & & $(72.5)$ & $(82.6)$ & & (71.8) & (79.6) & \\
\hline \multirow[t]{4}{*}{$\begin{array}{l}\text { Family } \\
\text { size }\end{array}$} & Less than 5 & 300 & 87 & 0.221 & 333 & 71 & 0.918 & 332 & 66 & 0.574 & 254 & 144 & 0.025 \\
\hline & & (39.7) & (35.4) & & (39) & $(38.6)$ & & (39.3) & $(37.1)$ & & $(36.6)$ & (43.9) & \\
\hline & More than 5 & 455 & 159 & & 521 & 113 & & 512 & 112 & & 440 & 184 & \\
\hline & & $(65.3)$ & $(64.6)$ & & (61) & (61.4) & & $(70.7)$ & $(62.9)$ & & $(63.4)$ & (37.1) & \\
\hline \multirow[t]{2}{*}{ Total } & & 246 & 755 & 1001 & 854 & 184 & 1038 & 844 & 178 & 1022 & 694 & 328 & 1022 \\
\hline & & (24.6) & $(75.4)$ & $(100)$ & (82.3) & (17.7) & (100) & (82.6) & (17.4) & (100) & (67.9) & (32.1) & (100) \\
\hline
\end{tabular}

$\square$ N. Mi, non Migraine; Mi, Migraine; N. IBS, non irritable bowel syndrome; IBS, irritable bowel syndrome; N. Ref, non reflux; Ref, reflux; N. Dy, dyspepsia; Dy, dyspepsia

$\square$ Data expressed as Number (percent)

ache society criteria had migraine. Migraine was more prevalent in female $(p<0.001)$, those with lower education $(p<0.001)$, and married $(p=0.004)$. Prevalence of IBS, reflux, and dyspepsia were $17.7 \%$ (184), 17.4\% (178), and $32.1 \%$ (328) based on Rome III criteria respectively.
Prevalence of different types of dyspepsia was $63.4 \%$ (208) epigastric pain syndrome (EPS), 24\% (79) post parandial distress (PDS) syndrome, 12.6\% (41) unspecific.

No significant association between demographic variables and IBS, reflux were found. But dyspepsia 
Table 2: Relation between Migraines with gastrointestinal functional disorders studies

\begin{tabular}{|c|c|c|c|c|c|}
\hline Gastrointestinal disorders & Mig & N. Mig & Total & OR $(\mathrm{CI}) *$ & P-value \\
\hline IBS & $82(33.3)$ & $96(12.7)$ & $178(17.8)$ & $3.43(2.40-4.89)$ & 0.001 \\
\hline N. IBS & $164(66.7)$ & $659(87.3)$ & $823(82.2)$ & & \\
\hline Ref & $70(28.5)$ & $154(13.8)$ & $174(17.4)$ & $1.68(1.19-2.35)$ & 0.001 \\
\hline N. Ref & $176(71.5)$ & $651(86.2)$ & $827(82.6)$ & & \\
\hline Dys & $101(41)$ & $221(29.3)$ & $322(32.1)$ & $1.68(1.23-2.29)$ & 0.001 \\
\hline N. Dys & $145(59)$ & $534(70.7)$ & $679(67.9)$ & & \\
\hline
\end{tabular}

N. Mig, non Migraine; Mig, Migraine; N. IBS, non irritable bowel syndrome; IBS, irritable bowel syndrome; N. Ref, non reflux; Ref, reflux; N. Dys, dyspepsia; Dys, dyspepsia

Data expressed as Number (percent); OR is unadjusted with (95\% Confidence Interval)

Table 3: Finding pathology based on migrain

\begin{tabular}{lcccc}
\hline Finding Pathology & Mig & N. Mig & OR (CI) & P-value \\
\hline Antrum Gastritis & $49(73.1)$ & $41(67.2)$ & $1.32(0.57-3.04)$ & 0.464 \\
\hline Antrum Germinal Center & $9(13.4)$ & $14(23.3)$ & $0.52(0.18-1.43)$ & 0.161 \\
\hline Antrum Atrophy & $2(3.0)$ & $4(6.5)$ & $0.43(0.03-3.20)$ & 0.339 \\
\hline Antrum Intestinal Metaplasia & $9(13.5)$ & $8(13.4)$ & $1.02(0.32-3.30)$ & 0.957 \\
\hline Antrum Helicobacter Pylori & $24(35.9)$ & $22(36.1)$ & $0.98(0.45-2.17)$ & 0.977 \\
\hline Body Gastritis & $4(6.1)$ & $4(6.5)$ & $0.90(0.16-5.09)$ & 0.891 \\
\hline Body Germinal Center & $1(1.5)$ & $1(1.6)$ & $0.90(0.01-72.53)$ & 0.946 \\
\hline Body Atrophy & $1(1.5)$ & $0(0.0)$ & - & 0.338 \\
\hline Body Intestinal Metaplasia & $0(0.0)$ & $1(1.6)$ & - & 0.292 \\
\hline Body Helicobacter Pylori & $0(0.0)$ & $1(1.7)$ & - & 0.292 \\
\hline Duodenum Germinal Center & $0(0.0)$ & $0(0.0)$ & - & - \\
\hline Duodenum giardiasis & $3(4.5)$ & $3(4.9)$ & $0.90(0.11-7.04)$ & 0.906 \\
\hline Duodenum Metaplasia & $10(15.0)$ & $10(16.4)$ & $0.89(0.30-2.16)$ & 0.819 \\
\hline Total pathology & 67 & 61 & - & - \\
\hline
\end{tabular}

N. Mi, non Migraine; Mi, Migraine

Data expressed as Number (percent)

Data analyzed by Pearson chi-square (Fisher exact).

was more prevalent in lower educated $(p=0.008)$, and married $(p=0.005)$ and in females $(p=0.002)$, and in those with smaller family size $(p=0.025)$.

Coexistence of migraine in persons with IBS was $33.3 \%(82), 28.5 \%$ (70) in reflux, and $41 \%(101)$ in dyspepsia. Our statistical analyses demonstrated that there were a strong significant association between migraine and these gastrointestinal diseases with odd ratio (OR) for IBS 3.43 (95\% CI: 2.40 - 4.89), for Reflux $1.68(1.19-2.35)$, for dyspepsia $1.68(1.23-2.29)$ with $P$-value $<0.001$. Coexistence of migraine and different types of dyspepsia was $24 \%$ (59) with EPS, $14.6 \%$ (36) with PDS, and $2.4 \%$ (6) with unspecific which were all significant statistically $(p<0.001)$. (Table 2$)$
Among all endoscopic findings, only hiatal hernia was statistically significant more prevalent in persons with migraine headache $(p=0.011)$. No pathologic finding on gastric or duodenal biopsies were associated with migraine headache. (Table 3 )

\section{DISCUSSION}

This study is to our best knowledge the first populationbased study to investigate the prevalence and association of migraine and gastrointestinal functional disorders in persons older than 15 years based on International Headache Society and Rome III criteria with correlation with endoscopic and pathologic findings. Using strict exclusion criteria we avoided the confounding effect of 
other comorbid conditions as well as the effect of use of analgesics or other drugs.

The prevalence of migraine in our study was $24.6 \%$. A systematic review and meta-analysis from Iran showed that prevalence of migraine in adolescence and adult was $7.14 \%$ to $18.11 \%$ respectively. ${ }^{16}$ In another systematic review and meta-analysis, it was demonstrated that migraine prevalence in children was from $5.6 \%$ to $8 \% .{ }^{17}$ Women were the dominant gender in our study group, as the prevalence of migraine is higher in females, this could explain the higher prevalence of migraine in our report. ${ }^{18-19}$ The life style and diet pattern of our study group could also had contribution. ${ }^{20}$

Based on our findings, the prevalence of IBS was $17.7 \%$. This was similar to the university-based study at shiraz university of medical sciences $(16.4 \%){ }^{21}$ In population-based studies conducted in China, ${ }^{22}$ Pakistan, ${ }^{23}$ and Saudi Arabia ${ }^{24}$ the prevalence of IBS was $13.25 \%$, $28.3 \%$, and $31.8 \%$, respectively. Various factors such as gender age, ethnicity, diet, and physical activity can influence on IBS prevalence..$^{25}$

With the launch of new Rome IV Diagnostic Criteria for Functional Gastrointestinal Disorders, the prevalence of IBS might be reported lower and some cases of IBS might be categorized under other titles. ${ }^{26}$

The prevalence of reflux was $17.4 \%$ in present study. Other population-based studies reported a prevalence of $10 \%$ to $20 \% .{ }^{27-28}$

The prevalence of dyspepsia in our study was $32.1 \%$. Systematic review and meta-analysis conducted by ElSerag et al. was shown that $10 \%$ to $40 \%$ of people had dyspepsia in the world which our result was being in this range. ${ }^{29}$ Iranian studies was demonstrated that the prevalence of dyspepsia was from $2.2 \%$ to $29.9 \%{ }^{30-31}$ Explanations for these differences may be due to the fact that some of these studies did not use Rome Diagnostic Criteria for Functional Gastrointestinal Disorders.

Our findings showed that $33.3 \%$ of IBS group had migraine headache. The same figure was reported from a population-based study in American. ${ }^{32-33}$ This association might be related to higher prevalence of anxiety/depression in both groups and may result from the so called visceral hyperalgesia. ${ }^{4,32}$ It is postulated that migraine patients with functional dyspepsia may have increased hypersensitivity to gastric distention and reduced tolerance to food com- pared to healthy people. ${ }^{34}$

Findings from other studies revealed that comorbid reflux in migraine patients had a range from $22 \%{ }^{10}$ to $42.6 \% .{ }^{5}$ Our result showed that this was $28.5 \%$. Although it is unclear why reflux is increasing among migraine patients, perhaps the correct explanation might be related to the common pathology in these diseases. Gastric reflux has been reported to precipitate attack of migraine..$^{34}$ Further Autonomic nervous system (ANS) dysfunction can play an important role in the etiology of both disorders..$^{35-36}$

Prevalence of migraine in dyspeptic patients was reported $60 \%$ (with confidence interval; $44 \%$ to $74 \%)^{37}$ in our study this was $41 \%$. As mentioned before abnormal visceral hypersensitivity may have role in both. ${ }^{38-41}$ Furthermore, several neuropeptides are involved for both these diseases. ${ }^{42-48}$ For instance the neuropeptide calcitonin gene-related peptide (CGRP) which is increased during migraine attacks can also cause dyspepsia. ${ }^{49}$

Few studies are published on prevalence of endoscopic and gastrointestinal histopathologic findings among patients with migraine..$^{50-52}$ These studies reported a high prevalence of gastritis in the antrum or gastric corpus, and duodenitis among migraine sufferers..$^{50-52}$ The main problem in these studies is not excluding patients on analgesics. In our study, the endoscopic and pathologic findings were not statistically significant between migraine and non-migraine groups except for the presence of hiatal hernia. This difference could be to our strict criteria in excluding persons on analgesic drugs.

The major strength of our study was its population based design with a large number of participants. However, it has some limitations including higher rate of participation of female subjects. The new Rome IV criteria was not available at the time of the study.

In summary, this study revealed an association between migraine and gastrointestinal functional disorders including IBS, reflux and dyspepsia. Hiatal hernia was the only abnormal endoscopic finding in patients with migraine headache. These finding may have implication in chronic management of patients with migraine.

\section{ACKNOWLEDGEMENTS}

This study was supported by a grant from Shiraz university of medical sciences to the corresponding author. The authors wish to thank Doctors Alireza Ta- 
vakolli, Mehrdad Afarid, Mohammad Mehdi Sagheb, Afkhamosadat Merikhi who participated in various stages of this study. Part of this study was presented in thesis of these colleagues. Authors also wish to thank the health care workers (Behvarz) in the health center of Baladeh and Mrs.Shahvaran who also provided extreme assistance in performing this study.

\section{CONFLICT OF INTEREST}

The authors declare no conflict of interest related to this work.

\section{REFERENCES}

1. Headache Classification Committee of the International Headache Society (IHS). The International Classification of Headache Disorders, 3rd edition (beta version). Cephalalgia 2013;33:629-808. doi: 10.1177/0333102413485658.

2. Shoeibi A, Olfati N, Soltani Sabi M, Salehi M, Mali S, Akbari Oryani M. Effectiveness of coenzyme Q10 in prophylactic treatment of migraine headache: an open-label, add-on, controlled trial. Acta Neurol Belg 2017;117:1039. doi:10.1007/s13760-016-0697-z.

3. Stovner L, Hagen K, Jensen R, Katsarava Z, Lipton R, Scher A, et al. The global burden of headache: a documentation of headache prevalence and disability worldwide. Cephalalgia 2007;27:193-210. doi:10.1111/j.14682982.2007.01288.x.

4. Camara-Lemarroy CR, Rodriguez-Gutierrez R, Monreal-Robles R, Marfil-Rivera A. Gastrointestinal disorders associated with migraine: A comprehensive review. World J Gastroenterol 2016;22:8149-60. doi: 10.3748/wjg.v22.i36.8149.

5. Aamodt AH, Stovner LJ, Hagen K, Zwart JA. Comorbidity of headache and gastrointestinal complaints. The Head-HUNT Study. Cephalalgia 2008;282:144-51. doi: 10.1111/j.1468-2982.2007.01486.x.

6. T. Noghani M, Rezaeizadeh H, Fazljoo SM, Keshavarz M. Gastrointestinal Headache; a Narrative Review. Emerg (Tehran) 2016;4:171-83.

7. Cole JA, Rothman KJ, Cabral HJ, Zhang Y, Farraye FA. Migraine, fibromyalgia, and depression among people with IBS: a prevalence study. BMC Gastroenterol 2006;6:26. doi:10.1186/1471-230X-6-26.

8. Jones R, Lydeard S. Irritable bowel syndrome in the general population. BMJ 1992;304:87-90. doi:10.1136/ bmj.304.6819.87.

9. Vandvik PO, Wilhelmsen I, Ihlebaek C, Farup PG. Comorbidity of irritable bowel syndrome in general practice: a striking feature with clinical implications. Aliment Pharmacol Ther 2004;20:1195-203. doi: 10.1111/j.1365-2036.2004.02250.x.8.

10. Katic BJ, Golden W, Cady RK, Hu XH. GERD prevalence in migraine patients and the implication for acute migraine treatment. J Headache Pain 2009;10:35-43. doi: 10.1007/s10194-008-0083-1.

11. Gasbarrini A, De Luca A, Fiore G, Gambrielli M, Franceschi F, Ojetti V, et al. Beneficial effects of Helicobacter pylori eradication on migraine. Hepatogastroenterology 1998;45:765-70.

12. Ciancarelli I, Di Massimo C, Tozzi-Ciancarelli MG, De Matteis G, Marini C, Carolei A. Helicobacter pylori infection and migraine. Cephalalgia 2002;22:222-5. doi: 10.1046/j.1468-2982.2002.00354.x.

13. Pinessi L, Savi L, Pellicano R, Rainero I, Valfre W, Gentile $\mathrm{S}$, et al. Chronic Helicobacter pylori infection and migraine: a case-control study. Headache 2000;40:836-9.

14. Classification and diagnostic criteria for headache disorders, cranial neuralgias and facial pain. Headache Classification Committee of the International Headache Society. Cephalalgia 1988;8 Suppl 7:1-96.

15. Drossman DA, Dumitrascu DL. Rome III: New standard for functional gastrointestinal disorders. $J$ Gastrointestin Liver Dis 2006;15:237-41.

16. Sadeghi O, Nasiri M, Saiedi SG. The Prevalence of Migraine in Different Parts of Iran: Review of the Current Evidence. Jundi J Chronic Dis Care 2015;4:e27678. doi: 10.5812/jjcdc.4(3)2015.27678.

17. Abu-Arafeh I, Razak S, Sivaraman B, Graham C. Prevalence of headache and migraine in children and adolescents: a systematic review of population-based studies. Dev Med Child Neurol 2010;52:1088-97. doi: 10.1111/j.1469-8749.2010.03793.x.

18. Stovner LJ, Andree C. Prevalence of headache in Europe: a review for the Eurolight project. $J$ Headache Pain 2010;11:289-99. doi: 10.1007/s10194-010-0217-0.

19. Sumanen MP, Ojanlatva A, Rantala A, Sillanmaki LH, Mattila KJ. Gender differences in sex life issues - a population-based study of migraine sufferers. BMC Fam Pract 2008;9:19. doi: 10.1186/1471-2296-9-19.

20. Finkel AG, Yerry JA, Mann JD. Dietary considerations in migraine management: does a consistent diet improve migraine? Curr Pain Headache Rep 2013;17:373. doi:10.1007/s11916-013-0373-4.

21. Bagheri-Lankarani K, Kodjori J, Agah S, Taghavi S, Rodgari A, Afrokhteh S. Irritable bowel syndrome: clinical manifestations and relation to lactase deficiency. Irn J Med Sc 1997;22:20-5.

22. Dong L, Dingguo L, Xiaoxing X, Hanming L. An epidemiologic study of irritable bowel syndrome in adolescents and children in China: a school-based study. $P e$ diatrics 2005;116:e393-6. doi: 10.1542/peds.2004-2764.

23. Naeem SS, Siddiqui EU, Kazi AN, Memon AA, Khan ST, Ahmed B. Prevalence and factors associated with irritable bowel syndrome among medical students of Karachi, Pakistan: a cross-sectional study. BMC Res Notes 2012;5:255. doi: 10.1186/1756-0500-5-255.

24. Ibrahim NK, Battarjee WF, Almehmadi SA. Prevalence and predictors of irritable bowel syndrome among medical students and interns in King Abdulaziz University, Jeddah. Libyan J Med 2013;8:21287. doi: 10.3402/ljm.v8i0.21287. 
25. Qureshi SR, Abdelaal AM, Janjua ZA, Alasmari HA, Obad AS, Alamodi A, et al. Irritable Bowel Syndrome: A Global Challenge Among Medical Students. Cureus 2016;8:e721. doi: 10.7759/cureus.721.

26. Mearin F, Lacy BE, Chang L, Chey WD, Lembo AJ, Simren M, et al. Bowel Disorders. Gastroenterology 2016;150:1393-1407.e5. doi: 10.1053/j.gastro.2016.02.031.

27. Nasseri-Moghaddam S, Mofid A, Ghotbi MH, Razjouyan $\mathrm{H}$, Nouraie M, Ramard AR, et al. Epidemiological study of gastro-oesophageal reflux disease: reflux in spouse as a risk factor. Aliment Pharmacol Ther 2008;28:144-53. doi: 10.1111/j.1365-2036.2008.03708.x.

28. Nusrat S, Nusrat S, Bielefeldt K. Reflux and sex: what drives testing, what drives treatment? Eur J Gastroenterol Hepatol 2012;24:233-47. doi: 10.1097/MEG.0b013e32834f6baa.

29. El-Serag HB, Talley NJ. Systemic review: the prevalence and clinical course of functional dyspepsia. Aliment Pharmacol Ther 2004;19:643-54. doi: 10.1111/j.1365-2036.2004.01897.x.

30. Khademolhosseini F, Mehrabani D, Zare N, Salehi M, Heydari S, Beheshti M, et al. Prevalence of dyspepsia and its correlation with demographic factors and lifestyle in shiraz, southern iran. Middle East J Dig Dis 2010;2:24-30.

31. Moghimi-Dehkordi B, Vahedi M, Khoshkrood Mansoori B, Kasaeian A, Safaee A, Habibi M, et al. Economic burden of gastro-oesophageal reflux disease and dyspepsia: A community-based study. Arab J Gastroenterol 2011;12:86-9. doi: 10.1016/j.ajg.2011.03.005.

32. Riedl A, Schmidtmann M, Stengel A, Goebel M, Wisser AS, Klapp BF, et al. Somatic comorbidities of irritable bowel syndrome: a systematic analysis. J Psychosom Res. 2008;64:573-82. doi: 10.1016/j.jpsychores.2008.02.021.

33. Tietjen GE, Herial NA, Hardgrove J, Utley C, White L. Migraine comorbidity constellations. Headache 2007;47:857-65. doi: 10.1111/j.1526-4610.2007.00814.x.

34. Pucci E, Di Stefano M, Miceli E, Corazza GR, Sandrini G, Nappi G. Patients with headache and functional dyspepsia present meal-induced hypersensitivity of the stomach. J Headache Pain 2005;6:223-6. doi: 10.1007/ s10194-005-0191-0.

35. Karamanolis G, Sifrim D. Developments in pathogenesis and diagnosis of gastroesophageal reflux disease. Curr Opin Gastroenterol 2007;23:428-33. doi: 10.1097/ MOG.0b013e328133f56a.

36. Peroutka SJ. Migraine: a chronic sympathetic nervous system disorder. Headache 2004;44:53-64. doi: 10.1111/j.1526-4610.2004.04011.x.

37. Kurth T, Holtmann G, Neufang-Huber J, Gerken G, Diener HC. Prevalence of unexplained upper abdominal symptoms in patients with migraine. Cephalalgia 2006;26:50610. doi: 10.1111/j.1468-2982.2005.01076.x.

38. Andrews PL, Sanger GJ. Abdominal vagal afferent neurones: an important target for the treatment of gastrointestinal dysfunction. Curr Opin Pharmacol 2002;2:6506. doi:10.1016/S1471-4892(02)00227-8.
39. Holtmann G, Goebell H, Jockenhoevel F, Talley NJ. Altered vagal and intestinal mechanosensory function in chronic unexplained dyspepsia. Gut 1998;42:501-6. doi: 10.1136/gut.42.4.501.

40. Moskowitz MA. Basic mechanisms in vascular headache. Neurol Clin 1990;8:801-15.

41. Sicuteri F, Nicolodi M. Visceral and somatic profiles of needless pain and nonpainful sensations in idiopathic headache. Clin J Pain 1991;7 Suppl 1:S38-43.

42. Edvinsson L. Calcitonin gene-related peptide (CGRP) and the pathophysiology of headache: therapeutic implications. CNS Drugs 2001;15:745-53. doi:10.2165/00023210200115100-00001.

43. Edvinsson L. Blockade of CGRP receptors in the intracranial vasculature: a new target in the treatment of headache. Cephalalgia 2004;24:611-22. doi: 10.1111/j.14682982.2003.00719.x.

44. Goadsby PJ, Edvinsson L, Ekman R. Vasoactive peptide release in the extracerebral circulation of humans during migraine headache. Ann Neurol 1990;28:183-7. doi: 10.1002/ana.410280213.

45. Gschossmann JM, Coutinho SV, Miller JC, Huebel K, Naliboff B, Wong HC, et al. Involvement of spinal calcitonin gene-related peptide in the development of acute visceral hyperalgesia in the rat. Neurogastroenterol Motil 2001;13:229-36. doi: 10.1046/j.1365-2982.2001.00262.x.

46. Kaneko H, Mitsuma T, Uchida K, Furusawa A, Morise K. Immunoreactive-somatostatin, substance $\mathrm{P}$, and calcitonin gene-related peptide concentrations of the human gastric mucosa in patients with nonulcer dyspepsia and peptic ulcer disease. Am J Gastroenterol 1993;88:898-904.

47. Plourde V, St-Pierre S, Quirion R. Calcitonin gene-related peptide in viscerosensitive response to colorectal distension in rats. Am J Physiol 1997;273:G191-6.

48. Tajti J, Uddman R, Edvinsson L. Neuropeptide localization in the "migraine generator" region of the human brainstem. Cephalalgia 2001;21:96-101. doi: 10.1046/j.14682982.2001.00140.x

49. Arakawa T, Uno H, Fukuda T, Higuchi K, Kobayashi K, Kuroki T. New aspects of gastric adaptive relaxation, reflex after food intake for more food: involvement of capsaicin-sensitive sensory nerves and nitric oxide. J Smooth Muscle Res 1997;33:81-8. doi:10.1540/jsmr.33.81.

50. Centonze V, Polito BM, Cassiano MA, Doronzo F, Ricchetti G, Portincasa P, et al. The dyspeptic syndrome in migraine: morphofunctional evaluation on 53 patients. Headache 1996;36:442-5. doi: 10.1046/j.1526-4610.1996.3607442.x.

51. Liu MT, Chim H, Guyuron B. Outcome comparison of endoscopic and transpalpebral decompression for treatment of frontal migraine headaches. Plast Reconstr Surg 2012;129:1113-9. doi: 10.1097/PRS.0b013e31824a2c31.

52. Mavromichalis I, Zaramboukas T, Giala M. Migraine of gastrointestinal origin. Eur J Pediatr 1995;154:406-10. doi:10.1007/BF02072116. 